\title{
AP-1 transcription factor decoy reduces the TGF-B1-induced cell growth in scleroderma fibroblasts through inhibition of cyclin $E$
}

\author{
JAE-WE CHO, YOUNG-CHANG CHA and KYU-SUK LEE \\ Department of Dermatology, Keimyung University School of Medicine, \\ 194 DongSan-Dong Jung-Gu, Daegu 700-712, Korea
}

Received July 30, 2007; Accepted October 4, 2007

\begin{abstract}
The transforming growth factor- $\beta$ (TGF- $\beta$ ) signaling pathway plays a key role in the abnormal accumulation of type I and III collagen of scleroderma. Activator protein-1 (AP-1) is a key regulatory protein in TGF-ß1-induced type I collagen synthesis. However, it is largely unknown whether AP-1 is involved in the cell proliferation of fibroblasts in scleroderma. In this study, we investigated the effects of the AP-1 oligo-deoxynucleotide (ODN) decoy on TGF-ß1induced cell growth in scleroderma fibroblasts. To investigate the inhibition of AP-1 ODN decoy on the growth rates of scleroderma fibroblasts through the regulation of cell cycle regulatory proteins, we transfected the AP-1 ODN decoy on scleroderma fibroblasts and analyzed the cell cycle regulatory proteins by RT-PCR and Western blot analysis. We found that the growth rates of normal fibroblasts and scleroderma fibroblasts showed similar rates. It is noteworthy that the scleroderma fibroblasts grew more rapidly than normal fibroblasts in the presence of TGF- $\beta 1$. Moreover, the transfection of AP-1 decoy ODN into scleroderma fibroblasts resulted in the down-regulation of the growth rates by the down-regulation of cyclin E. These results collectively suggest that AP-1 ODN decoy can down-regulate the growth rates of scleroderma fibroblasts, thus implying that AP-1 ODN decoy is a promising therapeutic tool for overcoming scleroderma.
\end{abstract}

\section{Introduction}

Scleroderma is a generalized disease which affects connective tissue in the skin and internal organs $(1,2)$. Although its precise molecular pathogenesis is still unclear, perturbation of transforming growth factor (TGF)- $ß$ signaling pathways in

Correspondence to: Dr Kyu-Suk Lee, Department of Dermatology, Keimyung University School of Medicine, 194 DongSan-Dong Jung-Gu, Daegu 700-712, Korea

E-mail: franzes@dsmc.or.kr

Key words: scleroderma, transforming growth factor- $\beta$, activator protein-1 oligodeoxynucleotides decoy, cyclin E fibroblasts is a key event in the development of scleroderma (3-6). TGF- $\beta$ is a major profibrotic cytokine, which regulates multiple cellular functions including differentiation, proliferation and induction of synthesis of extracellular matrix proteins (7). In human skin, TGF- 3 stimulates not only the synthesis and secretion of the major extracellular matrix proteins, especially type I collagen, but also the growth of dermal fibroblasts $(7,8)$. Activator protein-1 (AP-1) modulates the expression of type I collagen gene in skin fibroblasts $(9,10)$. Notably, AP-1 also stimulates cell cycle progression through the modulation of positive cell cycle regulators such as cyclin D1 and cyclin E (11). We reported that AP-1 oligodeoxynucleotide (ODN) decoy transfection inhibits the expression of type I collagen in scleroderma fibroblasts or keloid fibroblast $(12,13)$. However, it is not known whether inhibition of AP-1 binding by AP-1 decoy ODN transfection prevents the growth of scleroderma fibroblasts. In this study, we investigated whether the AP-1 decoy ODN modulates the growth rates of scleroderma fibroblasts through the regulation of cell cycle regulatory proteins.

\section{Materials and methods}

Cell culture. Primary cultures of normal human fibroblasts $(n=3$, mean age: 33$)$ and scleroderma fibroblasts $(n=3$, mean age: 34 ) were established from left-over adult skin following cosmetic surgery and being subcultivated on plastic culture dishes in Dulbecco's modified Eagle's medium (DMEM) supplemented with $10 \%$ fetal bovine serum (FBS), penicillin $(100 \mathrm{U} / \mathrm{ml})$, streptomycin $(100 \mu \mathrm{g} / \mathrm{ml})$ and amphotericin B $(1 \mu \mathrm{g} / \mathrm{ml})$. The cells were maintained in a humidified $5 \%$ $\mathrm{CO}_{2}-95 \%$ air incubator at $37^{\circ} \mathrm{C}$. Cells from the third and sixth passages were used in all experiments and viability was determined by trypan blue exclusion.

$T G F-\beta 1$ treatment. Confluent normal and scleroderma fibroblasts in $100 \mathrm{~mm}^{2}$-diameter petri dishes were treated with TGF- 31 ( $5 \mathrm{ng} / \mathrm{ml})$ for $24 \mathrm{~h}$ in the absence of FBS. TGF- $\beta 1$ was obtained from Sigma-Aldrich Co. (St. Louis, MO, USA) and was used after dilution in $95 \%$ ethanol.

Synthesis of ODN and selection of sequence targets. The AP-1 decoy ODN used in this study was kindly provided by Dr In Kyu Lee (Kyungpook National University School of 
Table I. DNA sequences of PCR primers used in this study.

\begin{tabular}{lccc}
\hline Name & & Primer sequences & Product size (bp) \\
\hline GAPDH & Sense & 5-CGTCTTCACCACCATGGAGA-3 & 300 \\
& Antisense & 5-CGGCCATCACGCCACAGTTT-3 & 402 \\
Cyclin D1 & Sense & 5-ACCTGGATGCTGGAGGTCTG-3 & \multirow{2}{*}{638} \\
& Antisense & 5-GAACTTCACATCTGTGGCACA-3 & 579 \\
Rb & Sense & 5-GGAAGGCAAACGTGACCGTT-3 & \\
& Antisense & 5-GGGACTTAAACGCCACTTAA-3 & 509 \\
CDK2 & Sense & 5-ATGTCAGAGAGAGAGCTTGG-3 & 336 \\
CDK4 & Antisense & 5-GTGCACTCCTGTTCTGACCT-3 & \\
& Sense & 5-CGGGATCCGGCGCCATGTCAGAAC-3 & \\
& Antisense & 5-CGGGAATTCGTGGGCGGATTAGGG-3 & \\
\hline
\end{tabular}

Medicine). The construction and stability of AP-1 decoy ODN were described previously (14).

The sequences of circular dumbell AP-1 decoy ODN (CDODN) against AP-1 binding sites and mismatched AP-1 decoy ODN (MODN, as a control) are as follows: (note, consensus sequences are underlined): CDODN: 5'-GGATCC ATGACTCAGAAGACGACACACGTCTTCTGAGTCAT-3'. MODN: 5'-GATCCAAATCTCAGAAGACGACACACGTC TTCTGAGATTT-3'. ODNs were annealed for $2 \mathrm{~h}$ with a steady temperature decline from 80 to $25^{\circ} \mathrm{C}$. T4 DNA ligase (1 unit) was added to the mixture, followed by incubation for $24 \mathrm{~h}$ at $16^{\circ} \mathrm{C}$ to generate a covalently ligated dumbell-shaped decoy ODN molecule. CDODN comprises of 2 loops and 1 stem containing two AP-1 consensus sequences in tandem.

Decoy ODN transfection using Lipofectamine Plus ${ }^{\circledR}$. AP-1 decoy ODN was transfected with normal and keloid fibroblasts for $24 \mathrm{~h}$ prior to TGF- $\beta 1$ treatment using Lipofectamine Plus (Gibco-Brl, USA). The cells were seeded at a density of $1-2 \times 10^{5}$ cells $/ 100 \mathrm{~mm}$ dish with $2 \mathrm{ml}$ DMEM and incubated overnight prior to transfection. At $40-60 \%$ confluency, a complex of decoy ODN $(4 \mu \mathrm{g})$ and Lipofectamine Plus reagent $(20 \mu \mathrm{l})$ was added to the washed cells and they were incubated in a serum-free medium for $15 \mathrm{~min}$.

Electrophoretic mobility shift assays (EMSA). The AP-1 decoy ODN was 5 '-end labeled with $\left[{ }^{32} \mathrm{P}\right]$-ATP using $\mathrm{T}_{4}$ polynucleotide kinase and purified by ethanol precipitation. Binding reactions were carried out in a buffer containing $10 \mathrm{mM}$ Tris $\mathrm{HCl}$ (pH 7.5), $50 \mathrm{mM} \mathrm{NaCl}, 0.5 \mathrm{mM}$ DTT, $10 \mathrm{mM}$ $\mathrm{MgCl}_{2}, 10 \%$ glycerol, $0.05 \% \mathrm{NP}-40$, and $2 \mathrm{mg}$ of poly (dI-dC) on ice for $15 \mathrm{~min}$. The assay mixture was incubated with radiolabeled decoy ODN for $30 \mathrm{~min}$ at $4^{\circ} \mathrm{C}$. After $6 \mathrm{x}$ strength dye solution $(0.1 \%$ bromophenol blue, $30 \%$ glycerol) was added, the mixture was immediately loaded and electrophoresed on a non-denaturing $6 \%$ polyacrylamide gel in $0.25 \mathrm{x}$ TBE (1 x TBE: $89 \mathrm{mM}$ Tris, $89 \mathrm{mM}$ boric acid, and $2.5 \mathrm{mM}$ EDTA) for $2 \mathrm{~h}$ at $200 \mathrm{~V}$. The gels were dried in a vacuum dryer at $80^{\circ} \mathrm{C}$ for $1.5 \mathrm{~h}$ and autoradiographed on a Fuji RX $\mathrm{X}$-ray film.
Northern blot analysis. Total RNA was isolated using the RNAzol $^{\mathrm{TM}}$ B (Biotecx laboratories Inc., Houston, TX, USA) according to the manufacturer's instructions and quantitated by spectrophotometry. Extracted RNA was analyzed by northern hybridization with various ${ }^{32} \mathrm{P}$-labeled cDNA probes. The $\left[{ }^{32} \mathrm{P}\right]$-cDNA-mRNA hybrids were visualized by autoradiography, and steady-state levels of mRNA were quantitated by laser densitometry (LKB Instruments, Bromma, Sweden). All quantitated mRNA levels were standardized to GAPDH mRNA levels in the same samples and all experiments were performed in triplicate.

Western blot. Cells were lysed in lysis buffer (10 mM Tris (pH 7.4), 5 mM EDTA, $130 \mathrm{mM} \mathrm{NaCl}, 1 \%$ Triton $\mathrm{X}-100$, PMSF $(10 \mu \mathrm{g} / \mathrm{ml})$, aprotinin $(10 \mu \mathrm{g} / \mathrm{ml})$, leupeptin $(10 \mu \mathrm{g} / \mathrm{ml})$, $5 \mathrm{mM}$ phenanthroline, and $28 \mathrm{mM}$ benzamidine- $\mathrm{HCl}$ ) for 30 min on ice. Lysates were clarified by centrifugation. Lysates were quantitated using the Bradford assay (Life Science Co., CA, USA) with bovine serum albumin as a reference standard. Proteins $(35 \mu \mathrm{l})$ were resolved by SDSPAGE (sodium dodecyl sulfate-polyacrylamide gels) and transferred to immobilon-P transfer membrane (Millipore Co., MA, USA). After incubation with primary antibodies, proteins were visualized by incubation with horseradish peroxidaseconjugated secondary antibodies, followed by ECL according to the manufacturer's instructions (Amersham Life Science Co., Buckinghamshire, UK). Primary antibodies against Rb (PharMingen Co., CA, USA), cyclin E, cyclin D1, cyclin dependent kinase 2 (CDK2), CDK4 and B-actin (Santa Cruz Co., CA, USA) were applied at optimized concentrations. The membrane was continuously incubated with appropriate secondary antibodies coupled to horseradish peroxidase, and developed in the ECL Western detection reagents (Amersham Pharmacia Biotech, Piscataway, NJ, USA).

Reverse transcription-polymerase chain reaction ( $R T-P C R)$. Total RNA was isolated from cultured skin fibroblasts using the RNAzol B (Biotecx laboratories Inc.) according to the manufacturer's instructions and quantitated by spectrophotometry. One microgram of total RNA was reverse 
(A)

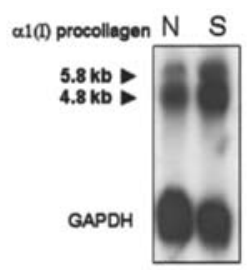

(B)

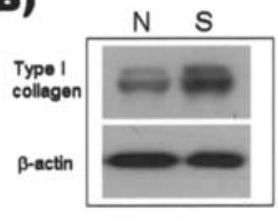

(C)

(D)

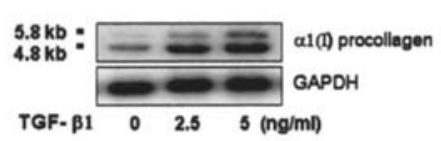

Figure 1. Expressions of type I collagen mRNA and protein in normal $(\mathrm{N})$ and scleroderma (S) fibroblasts. Cells were cultured in the normal media without TGF-B1 (A,B) or with TGF-B1 (C,D). Cell lysates were prepared for Northern blot $(A, C)$ and Western blot $(B, D)$ analysis. Similar results were found in two different experiments.

(A)

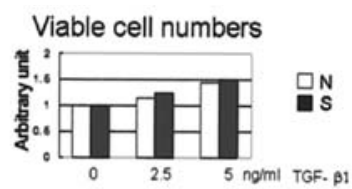

(B)

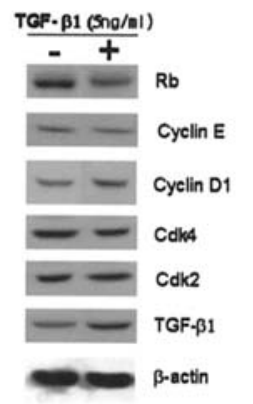

Figure 2. Increased viable cell number by TGF- $\beta 1$ treatment in scleroderma fibroblasts. Viable cells were counted using trypan blue exclusion assay $48 \mathrm{~h}$ after TGF- $\beta 1$ treatment with various concentrations in normal $(\mathrm{N})$ and scleroderma (S) fibroblasts (A). Proteins were also extracted $48 \mathrm{~h}$ after TGF- $\beta 1$ treatment in scleroderma fibroblasts, and cell cycle regulatory proteins were analyzed by Western blot analysis (B)

transcribed using M-MLV Reverse Transcriptase (Promega Co., Madison, WI, USA). The PCR reaction was carried out under the conditions recommended by the manufacturer's instructions (Takara Co., Otsu, Japan). Briefly, $50 \mu 1$ of a reaction mixture including 2.5 units of Taq polymerase (Takara Co.), $5 \mu 1$ of $10 \mathrm{x}$ buffer, $1.5 \mathrm{mM} \mathrm{MgCl}_{2}, 200 \mu \mathrm{M}$ dNTPs, $1 \mu 1$ of first-strand cDNA, and each 25 pmol of primer, were subjected to $28 \mathrm{PCR}$ cycles (denaturation at $94^{\circ} \mathrm{C}$ for $1.5 \mathrm{~min}$, annealing at $58^{\circ} \mathrm{C}$ for $1 \mathrm{~min}$, and polymerization at $72^{\circ} \mathrm{C}$ for $1 \mathrm{~min}$ ). The primer sequences used in this study are described in Table I.

\section{Results}

Effect of TGF- $\beta 1$ on expression of type I collagen in scleroderma fibroblasts. To confirm the established
(A)

(B)
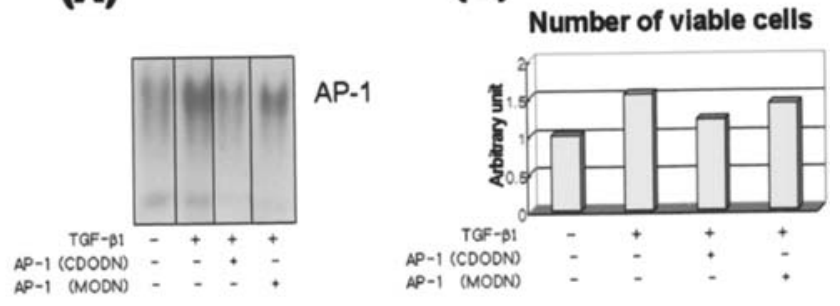

Figure 3. Inhibition of AP-1 DNA binding activity in scleroderma fibroblasts after AP-1 decoy CDODN transfection. The cells were transfected with AP-1 decoy CDODN or MODN, and these cells were cultured for $24 \mathrm{~h}$. AP-1 DNA binding activity (A) and the viable cell numbers (B) were analyzed by EMSA and trypan blue exclusion assay, respectively. Similar results were found in two different experiments.
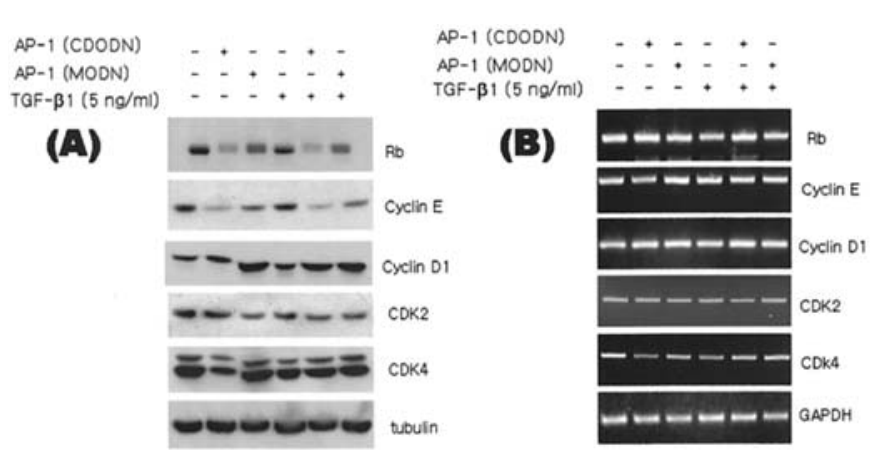

Figure 4. Expressions of cell cycle regulatory genes in scleroderma fibroblasts after AP-1 decoy ODN treatment. The cells were transfected with AP-1 decoy CDODN or MODN and then the cells were cultured in the absence or presence of TGF- $\beta 1$ for $24 \mathrm{~h}$. Cell lysates were prepared for Western blot (A) and RT-PCR (B) analysis. Similar results were found in two different experiments.

scleroderma fibroblast cell lines, the expression of type I collagen was analyzed by Northern blot and Western blot analysis. Expressions of type I collagen mRNA and protein were markedly increased in scleroderma fibroblasts compared to normal cells (Fig. 1A and B). To determine the effect of TGF- 31 on expressions of type I collagen mRNA and protein in scleroderma fibroblasts, cells were treated with various concentrations of TGF-B1 for $24 \mathrm{~h}$. As shown in Fig. 1C, expression of type I collagen mRNA dramatically increased in a dose-dependent manner. Increased expression of type I collagen mRNA was clearly visualized $24 \mathrm{~h}$ after TGF- $\beta 1$ $(5 \mathrm{ng} / \mathrm{ml})$ treatment. In agreement with Northern blot, an increased expression of type I collagen protein was observed in TGF-B1-treated scleroderma fibroblasts (Fig. 1D).

Effect of TGF- $\beta 1$ on cell proliferation rates in scleroderma fibroblasts. To determine the effect of TGF- 31 on the proliferation rates of scleroderma fibroblasts, viable cell counts were performed using trypan blue exclusion assay. We examined the proliferation rates of normal and scleroderma fibroblasts. Normal and scleroderma fibroblasts showed similar proliferation rates (data not shown). Notably, TGF- $\beta 1$ treated normal and scleroderma fibroblasts showed increased proliferation rates compared to non-treated cells, respectively (data not shown). However, the TGF- $\beta 1$-treated scleroderma 
fibroblasts grew more rapidly than the TGF- $\beta 1$-treated normal fibroblasts (Fig. 2A).

To investigate the effect of TGF- 31 on expressions of G1 cell cycle regulatory proteins in scleroderma fibroblasts, we performed immunoblotting of whole cell lysates using the anti-pRb, cyclin E, cyclin D1, CDK4, CDK2, and TGF- 31 antibodies. As shown in Fig. 2b, the expressions of $p R b$, cyclin E, CDK2, and CDK4 were not changed in the TGF-B1treated fibroblasts. It is noteworthy that the expressions of cyclin D1 and TGF- $\beta 1$ were increased in TGF- $\beta 1$-treated scleroderma fibroblasts (Fig. 2B).

Effect of AP-1 decoy ODN on the TGF- $\beta 1$-induced cell proliferation in scleroderma fibroblasts. To confirm the growth inhibitory effect of AP-1 decoy ODN, we transfected the CDODN or MODN into TGF-B1-treated scleroderma fibroblasts. The AP-1 binding activity in TGF-B1-treatedscleroderma fibroblasts was markedly decreased by CDODN transfection (Fig. 3A). The CDODN-transfected cells, but not the MODN-transfected cells, showed a decrease in cell numbers compared to TGF- 1 -treated cells, implying that the AP-1 decoy ODN modulates growth signals even under the influence of TGF-B1 (Fig. 3B).

Modulation of cell cycle regulatory proteins in scleroderma fibroblasts by AP-1 decoy ODN. To investigate the effect of AP-1 decoy ODN on expression of G1 cell cycle regulatory proteins, we performed immunoblotting of whole cell lysates using the anti-pRb, cyclin E, cyclin D1, CDK4, and CDK2 antibodies. As shown in Fig. 4A, the expressions of $\mathrm{pRb}$ and cyclin E proteins were markedly decreased by the CDODN transfection. The expressions of cyclin D1, CDK2, and CDK4 were found to be similar among cells. Notably, the expressions of G1 cell cycle regulatory genes such as $\mathrm{pRb}$ and cyclin E mRNA were not changed by CDODN transfection (Fig. 4B).

\section{Discussion}

Alterations in the TGF- $\beta$ signaling pathway have been proposed for key molecular events in the fibrosis of scleroderma skin lesions $(4,5,15)$. TGF- $\beta$ regulates cell replication and differentiation, bone formation, angiogenesis, cell cycle progression and cellular migration (16-18). TGF- $\beta$ stimulates the proliferation of fibroblasts, implying that downstreams of TGF- $\beta$ correlates with signal pathways of cell cycle progression. AP-1, one of down-stream signal molecules of TGF- $\beta$, is implicated in the transcriptional regulation of a wide range of genes participating in cell proliferation and ECM production under TGF- $\beta$ signaling cascades $(19,20)$. A new technique has been developed to inhibit target gene expression based on DNA technology such as antisense oligodeoxynucleotides (ODN), small interfering RNA (siRNA), ribozyme and decoy ODN (21-23). In this study, in order to develop a molecular therapeutic strategy based on decoy ODN, we investigated whether the AP-1 decoy ODN inhibits the growth of scleroderma fibroblasts. In the present study, we found that the scleroderma fibroblasts grew more rapidly than normal fibroblasts in the presence of TGF- $\$ 1$. Notably, AP-1 decoy ODN transfected-scleroderma fibroblasts showed decreased cell growth rates through the down-regulation of cyclin E.

Cell cycle progression is regulated by two protein classes, the cyclins and their kinase partners, CDKs $(24,25)$. Two families of cyclins are successively activated during the G1 phase, and thus also named as G1 cyclins $(26,27)$. G1 cyclins are composed of D-type and E-type cyclins. The D-type cyclins assemble with their catalytic partners, CDK4 and CDK6, followed by cyclin E interacting with its catalytic partner, CDK2. The subsequent cyclin-CDK complexes drive cell cycles from the G1 phase into the $S$ phase by the phosphorylation of $\mathrm{Rb}$. $\mathrm{Rb}$ is a central component of a transcriptional complex that inhibits the expression of many genes whose products are necessary for the G1/S transition and $S$ phase $(28,29)$. Therefore, cyclin D1 and cyclin E are the key regulatory proteins in the progression of $\mathrm{G} 1 / \mathrm{S}$ transition phases. Several studies have indicated that the activation of AP-1 correlates with accelerated cell cycle progression through the up-regulation of cyclin D1 and cyclin E $(30,31)$. Increased expressions of cyclin D1 and cyclin $\mathrm{E}$ were also observed in endometrial cancer or breast cancer showing increased AP-1 activities $(32,33)$. Furthermore, signaling pathways concerning the proliferation of fibroblasts may be associated with an increased production of type I collagen synthesis. Recent findings suggest that TGF-31induced connective tissue growth factor (CTGF) plays an important role in collagen synthesis and the proliferation of fibroblasts (34). In the case of cardiac fibroblasts, growth factors such as platelet-derived growth factor, insulin-like growth factor and fibroblast growth factor 2, play an important role in the regulation of fibroblast replication and collagen production $(35,36)$. In this study, it was investigated whether the AP-1 decoy ODN decreases the proliferation of scleroderma fibroblasts. The proliferation rates of AP-1 decoy ODN transfected scleroderma fibroblasts were about 2-fold decreased through the down-regulation of cyclin $\mathrm{E}$ expressions, followed by dephosphorylation of $\mathrm{Rb}$ protein. Further efforts are needed to evaluate the molecular mechanisms involved in AP-1 decoy ODN-induced downregulation of cyclin E expressions.

In conclusion, findings of the present study demonstrate that AP-1 decoy ODN inhibits not only the proliferation of scleroderma fibroblasts but also the expression of type I collagen, thereby suggesting that gene therapy using AP-1 ODN decoy may be used as a promising strategy for the regulation of collagen synthesis and cell growth. Further studies are required in order to prove that the blockade of the transcriptional factor AP-1 by AP-1 decoy ODN is sufficient in blocking the progression of scleroderma in vivo.

\section{Acknowledgements}

This work was supported by the research promoting grant from the Keimyung University Dongsan Medical Center in 2007.

\section{References}

1. Miller M: Scleroderma. Aust Fam Physician 22: 2112-2119, 1993.

2. Birdi N, Laxer RM, Thorner P, Fritzler MJ and Silverman ED: Localized scleroderma progressing to systemic disease. Case report and review of the literature. Arthritis Rheum 36: 410-415, 1993. 
3. Kawakami T, Ihn H, Xu W, Smith E, LeRoy C and Trojanowska M: Increased expression of TGF-beta receptors by scleroderma fibroblasts: evidence for contribution of autocrine TGF-beta signaling to scleroderma phenotype. J Invest Dermatol 110: 47-51, 1998 .

4. Cotton SA, Herrick AL, Jayson MI and Freemont AJ: TGF beta-a role in systemic sclerosis? J Pathol 184: 4-6, 1998.

5. Pannu J, Gore-Hyer E, Yamanaka M, et al: An increased transforming growth factor beta receptor type I:type II ratio contributes to elevated collagen protein synthesis that is resistant to inhibition via a kinase-deficient transforming growth factor beta receptor type II in scleroderma. Arthritis Rheum 50: 1566-1577, 2004.

6. Pannu J and Trojanowska M: Recent advances in fibroblast signaling and biology in scleroderma. Curr Opin Rheumatol 16: 739-745, 2004.

7. Chin D, Boyle GM, Parsons PG and Coman WB: What is transforming growth factor-beta (TGF-B)? Br J Plast Surg 57: 215-221, 2004

8. Denton CP and Abraham DJ: Transforming growth factor- $\beta$, and connective tissue growth factor: key cytokines in scleroderma pathogenesis. Curr Opin Rheumatol 13: 505-511, 2004.

9. Rossert J, Terraz C and Dupont S: Regulation of type I collagen genes expression. Nephrol Dial Transplant 15: 66-68, 2001.

10. Ghosh AK: Factors involved in the regulation of type I collagen gene expression: implication in fibrosis. Exp Biol Med 227: 301-314, 2002

11. Shaulian E and Karin M: AP-1 in cell proliferation and survival. Oncogene 20: 2390-2400, 2001

12. Kim CW, Suh SI, Sung SH, Lee IL and Lee KS: A transcriptional factor decoy against AP-1 suppresses TGF-beta1-induced type I collagen gene expression in cultured keloid fibroblasts. J Dermatol Sci 1: 49-51, 2005.

13. Cho JW, Kim JY, Kim CW and Lee KS: Down-regulation of TGF- $\beta 1$-induced type I collagen synthesis by AP-1 transcription factor decoy in scleroderma fibroblasts. J Dermatol Sci 3: 207-209, 2006

14. Ahn JD, Morishita R, Kaneda Y, et al: Transcription factor decoy for AP-1 reduces mesangial cell proliferation and extracellular matrix production in vitro and in vivo. Gene Ther 11: 916-923, 2004.

15. Trojanowska M: Molecular aspects of scleroderma. Front Biosci 7: 608-618, 2004

16. Zavadil J and Bottinger EP: TGF-beta and epithelial-tomesenchymal transitions. Oncogene 24: 5764-5774, 2005.

17. Ferrari N, Pfeffer U, Dell'Eva R, Ambrosini C, Noonan DM and Albini A: The transforming growth factor-beta family members bone morphogenetic protein-2 and macrophage inhibitory cytokine- 1 as mediators of the antiangiogenic activity of N-(4hydroxyphenyl) retinamide. Clin Cancer Res 11: 4610-4619, 2005.

18. Watts KL and Spiteri MA: Connective tissue growth factor expression and induction by transforming growth factor-beta is abrogated by simvastatin via a Rho signaling mechanism. Am J Physiol Lung Cell Mol Physiol 287: L1323-L1332, 2004.

19. Kerr LD, Miller DB and Matrisian LM: TGF-beta1 inhibition of transin/stromelysin gene expression as mediated through a Fos binding sequence. Cell 61: 267-278, 1990.
20. Mauviel A, Chen YQ, Dong W, Evans $\mathrm{CH}$ and Uitto J: Transcriptional interactions of transforming growth factor- $\beta$ with pro-inflammatory cytokines. Curr Biol 3: 822-831, 1993.

21. Tomita N, Azuma H, Kaneda Y, Ogihara T and Morishita R: Application of decoy oligodeoxynucleotides-based approach to renal diseases. Curr Drug Targets 5: 717-733, 2004.

22. Ahn JD, Morishita R, Kaneda Y, et al: Inhibitory effects of novel AP-1 decoy oligodeoxynucleotides on vascular smooth muscle cell proliferation in vitro and neointimal formation in vivo. Circ Res 90: 1325-1332, 2002.

23. Ahn JD, Morishita R, Kaneda Y, Lee KU, Park JY, Jeon YJ, Song HS and Lee IK: Transcription factor decoy for activator protein-1 (AP-1) inhibits high glucose- and angiotensin IIinduced type 1 plasminogen activator inhibitor (PAI-1) gene expression in cultured human vascular smooth muscle cells. Diabetologia 44: 713-720, 2001.

24. Murray AW: Recycling the cell cycle: cyclins revisited. Cell 116: 221-234, 2004.

25. Lukas J, Lukas C and Bartek J: Mammalian cell cycle checkpoints: signalling pathways and their organization in space and time. DNA Repair 3: 997-1007, 2004

26. Sherr CJ: Cell cycle control and cancer. Harvey Lect 96: 73-92, 2000

27. Sherr CJ: Mammalian G1 cyclins and cell cycle progression. Proc Assoc Am Physicians 107: 181-186, 1995.

28. Grzelakowska-Sztabert B: Cell cycle checkpoints - molecular background. Folia Morphol 63: 1-3, 2004.

29. Cobrinik D, Dowdy SF, Hinds PW, Mittnacht S and Weinberg RA: The retinoblastoma protein and the regulation of cell cycling. Trends Biochem Sci 17: 312-315, 1992.

30. Bu X, Avraham HK and Li X, et al: Mayven induces c-Jun expression and cyclin D1 activation in breast cancer cells. Oncogene 24: 2398-2409, 2005.

31. Phuchareon $\mathrm{J}$ and Tokuhisa T: Deregulated c-Fos/AP-1 modulates expression of the cyclin and the cdk gene in splenic $\mathrm{B}$ cells stimulated with lipopolysaccharide. Cancer Lett 92: 203-208, 1995.

32. Bamberger AM, Milde-Langosch K, Rossing E, Goemann C and Loning T: Expression pattern of the AP-1 family in endometrial cancer: correlations with cell cycle regulators. J Cancer Res Clin Oncol 127: 545-550, 2001.

33. Milde-Langosch K, Bamberger AM, Methner C, Rieck G and Loning T: Expression of cell cycle-regulatory proteins $\mathrm{rb}$, p16/MTS1, p27/KIP1, p21/WAF1, cyclin D1 and cyclin E in breast cancer: correlations with expression of activating protein-1 family members. Int J Cancer 15: 468-472, 2000.

34. Huang HC, Yang M, Li JZ and Wang HY: Connective tissue growth factor promotes the proliferation of myofibroblast through Erk-1/2 signaling pathway. Zhonghua Yi Xue Za Zhi 85: 1322-1326, 2005.

35. Chen MM, Lam A, Abraham JA, Schreiner GF and Joly AH: CTGF expression is induced by TGF-beta in cardiac fibroblasts and cardiac myocytes: a potential role in heart fibrosis. J Mol Cell Cardiol 32: 1805-1819, 2000.

36. Kapoun AM, Liang F, O'Young G, et al: B-type natriuretic peptide exerts broad functional opposition to transforming growth factor-beta in primary human cardiac fibroblasts: fibrosis, myofibroblast conversion, proliferation, and inflammation. Circ Res 94: 453-461, 2004. 